\title{
Prevalence of Hepatitis B Surface Antigen and Antibodies to Hepatitis C in the General Population of Benue State, Central Nigeria
}

\author{
Abraham O. Malu, ${ }^{1 *}$ Godwin I. Achinge, ${ }^{2}$ Priscilla M. Utoo, ${ }^{2}$ Jonathan T. Kur, ${ }^{3}$ and Solomon A. Obekpa ${ }^{2}$ \\ ${ }^{1}$ Jos University Teaching Hospital, Jos, Nigeria; ${ }^{2}$ Benue State University Teaching Hospital, Makurdi, Nigeria; ${ }^{3}$ Benue State Ministry of Health, \\ Makurdi, Nigeria
}

\begin{abstract}
There have been various estimates of the prevalence of hepatitis B and C infections in Nigeria. Recent studies have shown the prevalence to be lower than previously reported. The different populations studied might be responsible for this. It is important to have a real population data that would inform the policies to be adopted for eradication. We set out to determine the prevalence, risk factors, and pattern of hepatitis B and C in Benue State, Central Nigeria. Four thousand and five $(4,005)$ subjects, aged 1 year and older, were selected through a multistage random sampling to represent all parts of the state. Trained health workers administered a validated questionnaire. Rapid test kits were standardized and used in determining the prevalence of the respective viruses. Hepatitis B surface antigen (HBsAg) and antibodies to hepatitis $\mathrm{C}$ virus (anti-HCV) were found to be positive in $5 \%$ and $1 \%$, respectively, of subjects screened. The prevalence varied from one local government area to another, with HBsAg being $8 \%$ in the highest to $2 \%$ in the lowest LGC, and anti-HCV being $3 \%$ in the highest and $0 \%$ in the lowest. Age, previous close contact with a patient, and multiple sex partners were the most important risk factors for hepatitis B virus (HBV) infection, whereas age and previous blood transfusion were the most important risk factors for hepatitis $\mathrm{C}$ virus (HCV) infection. $\mathrm{HBV}$ immunization may be having an impact in reducing the prevalence of the virus. Nigeria appears to be moving from high endemicity to the intermediate one.
\end{abstract}

\section{INTRODUCTION}

Hepatitis $B$ and $C$ are responsible for most cases of chronic liver disease (chronic hepatitis, cirrhosis, and hepatocellular carcinoma) worldwide. They account for an even higher proportion of chronic liver diseases in sub-Saharan Africa and South East Asia. ${ }^{1-3}$ Studies in Nigeria have shown different prevalence over the years, depending on the population studied and the diagnostic method used. Most studies have given results that put Nigeria in the category of high prevalence (greater than $8 \%$ ). ${ }^{4-10}$

With immunization for HBV available and being used widely in children since $2004,{ }^{11,12}$ it is expected that the prevalence of HBV will gradually fall. Also, with the availability of curative treatment using highly effective oral treatment for $\mathrm{HCV}$, it is hoped that HCV will gradually be eliminated through treatment of those infected, thus reducing the pool of infective sources. ${ }^{13}$

Most studies in Nigeria did not use general population to determine the actual population prevalence. They relied on blood donors, antenatal clinic population, those who patronized health facilities for one reason or another, or those who responded to advertisement for mass screening at worship centers, schools, or market places. All of these introduced biases in the population actually screened..$^{5-12}$ A recent study by the Federal Ministry of Health tried to circumvent these problems by doing an actual population study. ${ }^{4}$ However, the study population of less than 1,000 subjects for a country of more than 180 million people by then was not likely to give a true picture. It is unfortunately the current point of reference for the prevalence of HBV and HCV in Nigeria, and it gives HBV prevalence of $12.2 \%$ and $\mathrm{HCV}$ prevalence of $2.3 \%$. This maintains Nigeria in the hyper-endemicity zone. One expects that the universal policy on immunization of all new-born and infants since 2004 would have the effect of reducing the prevalence of hepatitis B surface antigen (HBsAg). A study of

*Address correspondence to Abraham O. Malu, Department of Medicine, University of Jos, Jos 930001, Nigeria. E-mail: aomalu@ gmail.com the adult general population carried out by Lagos State government gave a completely different picture, where HBV prevalence was less than $2.1 \%$ and $\mathrm{HCV}$ much lower at $0.1 \% .{ }^{14}$ A study from Cross River state among young children aged 11-19 years also gave a much lower figure of HBsAg of $1.2 \% .{ }^{15} \mathrm{WHO}$ modeling for Africa puts the current prevalence of HBV at $4.6-8.5 \% .^{16}$

With all these discordant results being reported in different parts of the country and WHO modeling being very different from the currently used prevalence of $12.2 \%$ for HBV, it became desirable for us to carry out a systematic populationbased study of the prevalence of HBsAg and antibodies to hepatitis $\mathrm{C}$ (anti-HCV). The findings from the study will help both Nigeria and WHO determine whether or not Nigeria has moved from the hyperendemic to moderate or even lowendemicity status as a result of infant immunization and other control measures.

Treatment for HCV is now highly effective. Although the initial cost of treatment was prohibitive, it has come down substantially. Elimination of $\mathrm{HCV}$ is, therefore, a worldwide target now. ${ }^{17}$ The Federal Government of Nigeria has outlined a policy on tackling the problem of hepatitis, and treatment of $\mathrm{HCV}$ is an important aspect of this. ${ }^{18}$ Some states have already keyed into the initiative and are subsidizing treatment. To help states plan and budget properly, the true prevalence of $\mathrm{HCV}$ is important. The results from this study of anti-HCV in Benue State will provide information that will be useful in helping the state, Nigeria, and other partners implement the policy on providing treatment for patients with HCV infection.

An accurate figure on both viruses is important because it is such figures that may help the state government work with other agencies to develop policy on control and treatment of those already infected with the viruses.

\section{SUBJECTS AND METHODS}

This was a cross-sectional population-based study using the multistage random sampling to obtain the study subjects as shown in Table 1. We selected two local government areas 
TABLE 1

Communities in Benue State of Nigeria screened for hepatitis B and C

\begin{tabular}{|c|c|c|c|}
\hline & Senatorial district (with 2016 projected population) & Local government area (with 2016 projected population) & Enumeration area \\
\hline 1 & Zone A $(2,020,634)$ & $\begin{array}{l}\text { Konshisha }(303,284) \\
\text { Kwande }(334,228)\end{array}$ & $\begin{array}{l}\text { Ikyurav } \\
\text { Mbavaa } \\
\text { Mbayoor } \\
\text { Mbakyor }\end{array}$ \\
\hline 2 & Zone B $(1,904,249)$ & $\begin{array}{l}\text { Makurdi }(399,678) \\
\text { Buruku }(273,784)\end{array}$ & $\begin{array}{l}\text { Lobi } \\
\text { Agwanjukun } \\
\text { Binev } \\
\text { Mbakyaan }\end{array}$ \\
\hline 3 & Zone C $(1,745,428)$ & $\begin{array}{l}\text { Oju }(228,783) \\
\text { Ogbadibo }(172,971)\end{array}$ & $\begin{array}{l}\text { Aenu } \\
\text { Okpokpo } \\
\text { Ahaje } 1 \\
\text { Aeona } 1\end{array}$ \\
\hline
\end{tabular}

(LGAs) from each of the three senatorial districts. The names of the local governments in each district were written on pieces of paper of equal size. They were then folded and put in a basket, which was then shaken and one of us dipped a hand in the container without looking. The two local governments in each district were chosen through this method. The same process was used in selecting the two enumeration areas (political wards) from each chosen local government. At the ward level, compounds to be studied were selected by the investigator based on convenience. The compound of the community leader in the locality was usually first selected to promote acceptance by the community, followed by the compounds closet to that house in an expanding manner. In each compound or house entered, all consenting subjects aged 1year and older were recruited.

A pre-validated interviewer-administered questionnaire was used. The enumerators were community extension workers or officers from the local area or doctors who spoke both English and the local language fluently. They were recruited and trained in the administration of the questionnaire in English and interpreting it in the local language where appropriate. Laboratory technicians already familiar with using rapid diagnostic test kits were further trained to standardize their methods. The same technicians were used throughout the study.

Rapid diagnostic test kits (Nantong Egens Diagnosis Biotechnology Co. Ltd., Rugao Jiangsu Porvince, China) were used. For HBV, Swecare Rapid One-Step strips, which test based on the chromatographic immunoassay method, were used. The manufacturer stated their sensitivity to be $99.0 \%$, specificity of $97.0 \%$, and accuracy of $98.5 \%$. For HCV BioCheck One-Step Rapid Test kits (Blue Cross Bio-Medical (Beijing) Co. Ltd., Beijing, China) were used. They also worked on the chromatographic immunoassay method. Its sensitivity is reported to be $99.8 \%$, specificity of $99.9 \%$, and accuracy of $99.9 \%$. Each packet of the kits was evaluated further to authenticate their performance by using the positive and negative controls for both viruses obtained from the Benue State University Teaching Hospital laboratory. Findings using the strips were found to be consistent with the positive and negative samples from the hospital that had been determined by ELISA.

The test method enclosed in the packet by the manufacturer of the kits was used. In brief, each subject's index finger was cleaned with spirit and then dried with a dry cotton swab. It was then pricked using a sterile lancet. Two drops of blood were placed at the center of the "sample pad" on the test strip resting on a flat clean surface, and then two drops of buffer was added. Strips were then observed for 15 minutes for HBV and 10 minutes for HCV. When two colored bands appeared, it was regarded as positive for $\mathrm{HBsAg}$ or anti-HCV, respectively. When only one band appeared in the control portion of the strip, it was regarded as negative. When the control band did not appear but there was a band visible at the test portion, the test was repeated, using a different strip. The same repeat testing was performed when there was no band at both the control and test locations.

Blood samples were collected from every 20th person, and every person positive for HCV antibodies, and brought back to the town, where it was centrifuged and serum kept at $-20^{\circ} \mathrm{C}$. The plan was to use the serum of every 20th person for analysis for other markers of HBV and to use the serum of those positive for $\mathrm{HCV}$ by rapid testing for $\mathrm{HCV}$ confirmation through polymerase chain reaction (PCR). However, no funds were available for the HCV PCR, so it was not performed. The test results for HBV markers are a subject for another report.

Ethical approval for the study was obtained from the Benue State University Teaching Hospital Research and Ethics Committee BSUTH/MKD/HREC/204B/2017/0014.

Each LGC chairman and the local chiefs at each level were visited to obtain their consent for the study to be carried out in their domains. Each individual gave informed verbal consent following explanation of what the study entailed, except that parents or other legitimate custodians gave consent on behalf of the children less than 18 years, and those aged 12-18 were further required to give their own consent for inclusion in the study. Confidentiality was observed when asking intimate questions.

The data collected were entered into excel sheets, cleaned, and transferred to Stata Corp statistical package for analysis. Data were presented in tables as frequencies and percentages. Association between variables was computed using the chi-square test, odds ratio (OR), and $\mathrm{Cl}$. A $P$-value of $<0.05$ was considered significant.

\section{RESULTS}

In all, 4,049 subjects were included in the study. After cleaning the data, 4,005 had complete data and were available for analysis. The 44 who were not included in the analysis were mainly because of missing or inconsistent data entry by the enumerators.

The demographic characteristics of the subjects are shown in Table 2. Subjects younger than 20 years constituted more 
TABLE 2

Sociodemographic characteristic of respondents screened for Hepatitis $B$ and $C$ in Benue State $(N=4,005)$

\begin{tabular}{lrr}
\hline Characteristic & Frequency & Percentage (\%) \\
\hline Age (years) & & \\
$0-10$ & 1,235 & 30.8 \\
$11-20$ & 953 & 23.8 \\
$21-30$ & 687 & 17.2 \\
$31-40$ & 431 & 10.8 \\
$41-50$ & 295 & 7.4 \\
$51-60$ & 186 & 4.6 \\
61 and above & 218 & 5.4 \\
Gender & & \\
Male & 2,027 & 50.6 \\
Female & 1,978 & 49.4 \\
Location & & \\
Urban & 801 & 20.0 \\
Rural & 3,204 & 80.0 \\
Ethnic group & & \\
Tiv & 2,242 & 56.0 \\
Idoma & 687 & 17.2 \\
Igede & 584 & 14.6 \\
Other & 492 & 12.2 \\
Local government & & \\
Buruku & 678 & 16.9 \\
Konshisha & 634 & 15.8 \\
Kwande & 746 & 18.6 \\
Makurdi & 801 & 20.0 \\
Ogbadigbo & 578 & 14.5 \\
Oju & 568 & 14.2 \\
\hline
\end{tabular}

than $55 \%$ of the population studied, whereas those older than 60 years were less than $5 \%$. The male:female ratio was 1.04 . Twenty percent of subjects lived in the urban area of Makurdi, whereas the rest of the subjects were from rural areas. The three largest tribes of Tiv, Idoma, and Igede constituted $87.6 \%$ of the subjects.

Two hundred and one (201) or $5.0 \%$ tested positive for HBsAg, whereas 38 (1.0\%) tested positive for HCV antibodies. The distribution of HBV according to age and vaccination status is shown in Tables 3 and 4, whereas Table 5 shows the distribution of HBV and HCV by LGAs.

The hepatitis B sero-status according to different parameters is shown in Table 6. Older age (20 years and older) was highly associated with being positive for $\operatorname{HBsAg}(P=$ 0.0000074 ; $\mathrm{OR}=1.88, \mathrm{Cl}=1.505-2.501)$. A history of close contact with a person positive for HBV infection was also highly associated with being positive $(P=0.0000021$; OR $=$

TABLE 3

Age distribution of subjects and their HBV status

\begin{tabular}{lcrc}
\hline & \multicolumn{2}{c}{ HBsAg status, $n(\%)$} & \\
\cline { 2 - 3 } Age group (years) & HBsAg positive & HBsAg negative & Total subjects, $n(\%)$ \\
\hline $0-5$ & $3(0.5)$ & $653(99.5)$ & $656(100)$ \\
$6-10$ & $8(1.3)$ & $606(98.7)$ & $614(100)$ \\
$11-15$ & $26(5.1)$ & $479(94.9)$ & $505(100)$ \\
$16-20$ & $45(10.0)$ & $403(90.0)$ & $448(100)$ \\
$21-25$ & $39(11.4)$ & $304(88.6)$ & $343(100)$ \\
$26-30$ & $31(9.0)$ & $313(91.0)$ & $344(100)$ \\
$31-35$ & $15(6.6)$ & $214(93.5)$ & $229(100)$ \\
$35-40$ & $14(6.9)$ & $188(93.1)$ & $202(100)$ \\
$41-45$ & $10(6.9)$ & $135(93.1)$ & $145(100)$ \\
$46-50$ & $6(4.0)$ & $144(96.0)$ & $150(100)$ \\
51 and older & $4(0.9)$ & $349(99.2)$ & $352(100)$ \\
Total & $201(5.0)$ & $3,804(95.0)$ & $4,005(100)$ \\
\hline \multicolumn{2}{l}{ HBsAg = hepatitis B surface antigen. } &
\end{tabular}

TABLE 4

Effect of vaccination on HBsAg status

\begin{tabular}{lccr}
\hline & \multicolumn{2}{c}{ HBsAg status, $n(\%)$} & \\
\cline { 2 - 3 } HBV vaccination & Positive & Negative & \multicolumn{1}{c}{ Total } \\
\hline Yes & $29(0.7)$ & $923(23.1)$ & $952(23.8)$ \\
No & $172(4.3)$ & $2,881(71.9)$ & $3,053(76.2)$ \\
Total & 201 & 3,804 & $4,005(100)$ \\
\hline HBsAg = hepatitis B surface antigen. Statistics: $\mathrm{X}^{2}=10.19, P=0.001 ;$ prevalence for the \\
vaccinated = 3.1\%; prevalence for the unvaccinated $=5.6 \%$.
\end{tabular}

2.25, $\mathrm{Cl}=1.589-3.184)$. Multiple sexual partners were associated with being positive for $\mathrm{HBsAg}(P=0.005096$; $\mathrm{OR}=$ 1.643 and $\mathrm{Cl}=1.121-2.408$ ). Tribal marks, sharing sharps, previous surgery, and transfusion did not predispose to infection with HBV in this study.

Table 7 shows the prevalence of HCV antibodies according to different patient characteristics. Again, older age was a great risk factor $(P=0.00035, \mathrm{OR}=6.78, \mathrm{Cl}=2.829-16.25)$. Unlike for HBV, previous transfusion predisposed to having evidence of $\mathrm{HCV}$ infection $(P=0.007301, \mathrm{OR}=2.696$ and $\mathrm{Cl}=$ 1.178-6.172). History of sharing sharps was almost significant at $P=0.056$. History of multiple sexual partners was not a risk factor for being HCV antibody positive.

\section{DISCUSSION}

The findings from this study are in line with some of the more recent studies in Nigeria. The statewide study from Lagos and the study among school children from Calabar both show that the prevalence of hepatitis is not as high as previously reported. ${ }^{14,15}$ There are many possible reasons why this may be the case. In the first place, most of the previous studies with higher prevalence depended on specific populations of people who came to the hospital, such as blood donors, antenatal clinic attendees, or outpatient populations. ${ }^{5-12}$ All these methods have their drawbacks. Many commercial blood donors have higher rate of $\mathrm{HIV}, \mathrm{HBV}$, and $\mathrm{HCV}$ infection compared with others, ${ }^{19,20}$ so using blood donors is likely to predispose to getting higher rates of prevalence. Some of them exhibit risky behavioral tendencies. They use the money collected to indulge in practices known to predispose to hepatitis infection.

Antenatal attendees are obviously sexually active, and sex is one of the means of transmission of hepatitis. In addition, some of them have had gynecological or obstetric procedures, and we know surgical procedures predispose to infection.

Even when "general populations" were used by advertising free screening services at certain locations, those who responded were self-selected. Some had previously been tested positive and wanted to confirm by coming to such places. Others knew they had exposed themselves to risky behavior and wanted to know if they had been infected. In the current survey, we had people who came from compounds not selected for the study because they had been tested positive elsewhere and wanted to confirm. They were tested but not included in the study because they were not part of the preselected population. If care is not taken to exclude people who want to take advantage of mass testing and confirm their status, we may include motivated and selected people, which will introduce bias in the results.

Most of the specific populations previously studied eliminated children by their very nature, such as blood donors or 
TABLE 5

Distribution of HBV and hepatitis $\mathrm{C}$ virus ( $\mathrm{HCV}$ ) according to local government areas

\begin{tabular}{lcccc}
\hline \multicolumn{1}{c}{ LGA (total) } & Both viruses negative & HBV positive, $n(\%)$ & HCV positive, $n(\%)$ & Both positive, $n$ (\%) \\
\hline Buruku (678) & 601 & $54(8)$ & $20(3.0)$ & $3(0.4)$ \\
Konshisha (634) & 598 & $33(5.2)$ & $3(0.5)$ & $0(0)$ \\
Kwande (746) & 700 & $41(5.5)$ & $5(0.6)$ & $0(0)$ \\
Makurdi (801) & 762 & $33(4.1)$ & $6(0.7)$ & $0(0)$ \\
Ogbadibo (578) & 567 & $11(2)$ & $0(0)$ & $0(0)$ \\
Oju (568) & 542 & $28(4.6)$ & $0(0)$ & 0 \\
Total (4,005) & 3,770 & $198(4.9)$ & $34(0.9)$ & $3(0.1)$ \\
\hline
\end{tabular}

pregnant women. They were, therefore, not really populationbased studies because they eliminated a large section of the population.

Aforementioned factors might have contributed to the relatively high prevalence rates previously reported in Nigeria.

More recent systematic population studies show lower rates. The studies from Lagos ${ }^{14}$ used random sampling for the adult population, and their findings were even lower than the ones currently being reported. A recent study among school children from the Cross River state of Nigeria ${ }^{15}$ also found a much lower rate than that previously reported. WHO modeling indicated that $\mathrm{HBsAg}$ prevalence in the African region is in the region of $4.6-8.5 \%$, which closely agrees with the findings of this study. ${ }^{16}$

The recent nationwide survey ${ }^{4}$ attempted to overcome the deficiency inherent in the use of hospital-based subjects. It still found high prevalence of $12.2 \%$ for HBV and $2.3 \%$ for HCV. Although this was possibly a well-designed study, certain findings raised some questions to be answered. Nigerian population has a pyramid with a wide base and a narrow tip. However, the population of children in their study was relatively low and those younger than 20 years were only $14.7 \%$, with the total population of those younger than 30 years only $35 \%$, instead of the expected above $50 \%$. One is left guessing as to whether the enumerators actually followed their briefs and did what they were expected to do. In the same vein, the female subjects were only $45.6 \%$, far below the almost $1: 1$ ratio in the 2018-estimated population. The present study had those younger than 20 years constituting $55 \%$ and male to female ratio of 50.9:49.1, which is much closer to the expected distribution, suggesting the subject selection in the current study was more representative. Less than 1,000 subjects were covered in the national survey, whereas the present study had more than 4,000 in just one of the 36 states. It is, therefore, more powered to bring out the actual prevalence of hepatitis in at least this part of Nigeria.

The figures around $12 \%$ have been reported for years. ${ }^{5-13}$ One would expect that with the inclusion of HBV immunization for children for more than 10 years, the prevalence should be falling. More recent studies, including the present study, support this thinking. It is surprising that the national survey, which included children, found such a high prevalence. Its small sample size and unexplained skewed age and gender distribution might explain the findings. The present study shows a low prevalence of HBsAg in the young, increasing gradually to a peak of $11.7 \%$ in the age group of $21-25$ years and beginning a gradual fall thereafter. This could be due to the fact that younger people had less time to be exposed to the virus in the time they were born or due to the fact that more of them were vaccinated and so protected, even with exposure to the virus. Table 4 shows that even when the whole population is considered, those who have been vaccinated are

TABLE 6

Hepatitis B sero-status in Benue State against respondents' characteristics

\begin{tabular}{|c|c|c|c|}
\hline \multirow[b]{2}{*}{ Characteristic } & \multicolumn{2}{|c|}{ HBV status } & \multirow[b]{2}{*}{ Statistics } \\
\hline & Positive & Negative & \\
\hline \multicolumn{4}{|l|}{ Age (years) } \\
\hline$>20$ & 119 & 1,679 & \multirow[t]{2}{*}{$x^{2}=18.76, P=0.000007411$} \\
\hline$\leq 20$ & 82 & 2,169 & \\
\hline \multicolumn{4}{|c|}{ Any close contact with infected person } \\
\hline Yes & 35 & 312 & \multirow[t]{2}{*}{$x^{2}=21.11, P=0.000002127$} \\
\hline No & 166 & 3,536 & \\
\hline \multicolumn{4}{|c|}{ Number of sexual partners } \\
\hline$\geq 2$ & 45 & 408 & \multirow[t]{2}{*}{$x^{2}=6.601, P=0.005096$} \\
\hline 1 & 80 & 1,192 & \\
\hline \multicolumn{4}{|l|}{ Ever shared sharps } \\
\hline Yes & 118 & 1,241 & \multirow[t]{2}{*}{$x^{2}=2.526, P=0.56$} \\
\hline No & 83 & 1,598 & \\
\hline \multicolumn{4}{|c|}{ Previous surgical procedure } \\
\hline Yes & 22 & 380 & \multirow[t]{2}{*}{$x^{2}=0.2446, P=0.3105$} \\
\hline No & 179 & 3,468 & \\
\hline \multicolumn{4}{|c|}{ Practice of intravenous drug use } \\
\hline Yes & 12 & 207 & \multirow[t]{2}{*}{$x^{2}=0.1303, P=0.3591$} \\
\hline No & 189 & 3,641 & \\
\hline \multicolumn{4}{|c|}{ Had previous blood transfusion } \\
\hline Yes & 15 & 302 & \multirow[t]{2}{*}{$X^{2}=0.03935, P=0.4214$} \\
\hline No & 186 & 3,546 & \\
\hline
\end{tabular}


TABLE 7

Hepatitis C sero-status against respondents' characteristics

\begin{tabular}{|c|c|c|c|}
\hline \multirow[b]{2}{*}{ Characteristics } & \multicolumn{2}{|c|}{ Hepatitis $C$ virus status } & \multirow[b]{2}{*}{ Statistics } \\
\hline & Positive & Negative & \\
\hline \multicolumn{4}{|l|}{ Age (years) } \\
\hline$>20$ & 32 & 1,766 & \multirow[t]{2}{*}{$x^{2}=24.62, P=0.0000349$} \\
\hline$\leq 20$ & 6 & 2,245 & \\
\hline \multicolumn{4}{|c|}{ Ever shared sharps } \\
\hline Yes & 17 & 1,307 & \multirow[t]{2}{*}{$X^{2}=2.526, P=0.056$} \\
\hline No & 21 & 2,704 & \\
\hline \multicolumn{4}{|c|}{ Any close contact with infected person } \\
\hline Yes & 5 & 342 & \multirow[t]{2}{*}{$X^{2}=1.03, P=0.1560$} \\
\hline No & 33 & 3,667 & \\
\hline \multicolumn{4}{|c|}{ Presence of tribal marks } \\
\hline Yes & 10 & 879 & \multirow[t]{2}{*}{$x^{2}=0.4255, P=0.2571$} \\
\hline No & 28 & 3,125 & \\
\hline \multicolumn{4}{|c|}{ Previous surgical procedure } \\
\hline Yes & 5 & 397 & \multirow[t]{2}{*}{$x^{2}=0.4474, P=0.2518$} \\
\hline No & 33 & 3,614 & \\
\hline \multicolumn{4}{|c|}{ Practice of intravenous drug use } \\
\hline Yes & 1 & 218 & \multirow[t]{2}{*}{ Fisher's exact $=0.3822$} \\
\hline No & 37 & 3,793 & \\
\hline \multicolumn{4}{|c|}{ Had previous blood transfusion } \\
\hline Yes & 7 & 310 & \multirow{2}{*}{$X^{2}=5.964, P=0.007301$} \\
\hline No & 31 & 3,701 & \\
\hline \multicolumn{4}{|c|}{ Sexual partners } \\
\hline$>1$ & 7 & 446 & \multirow[t]{2}{*}{$x^{2}=0.02337, P=0.4393$} \\
\hline 1 & 21 & 1,251 & \\
\hline
\end{tabular}

less likely to be carriers of HBV. The finding that the prevalence fell in the older age groups (older than 30 years) may be due to many of them who were positive having died of liver disease, hence leaving a population with a lower prevalence.

Hepatitis C prevalence was also noted in this study to be lower than expected, and the possible reasons are the same as for HBV. The inclusion of children in the general population lowered the prevalence because HCV infection usually rises more with age. One had expected it to be higher in this part of the country, bearing in mind that it is reported to be high in the Cameroun, and Benue State shares a border with the Republic of the Cameroun. The reason why the prevalence was so low needs further research. It is worth noting that the population survey in Lagos reported an even lower prevalence. ${ }^{14}$

Even within Benue State, the prevalence of both HBV and $\mathrm{HCV}$ varied from one local government to the other. For hepatitis $\mathrm{B}$, Buruku local government had the highest prevalence (8\%), whereas Ogbadibo had the lowest (2\%). The reason for such difference is not obvious, but it shows the importance of such surveys all over the country before one can target areas with much higher prevalence to make the greatest impact.

The older subjects had higher prevalence of HBsAg as would be expected if immunization was having impact on the epidemiology of hepatitis $B$. Having a family member positive for HBV also was a risk factor for getting infected. Such close contact provides opportunities for infected body fluids to pass from one family member to another. Because this study included all members of households, it is even possible that it overestimated the prevalence of HBV in the general population because of clustering in some families. However, this was not looked at in detail in this study.

Makurdi, the state capital had similar prevalence as the rural areas. The study from Lagos showed lower rates in the urban areas compared with the rural ones. ${ }^{14}$ On the contrary, a study of urban versus rural areas in China did not find any difference in the prevalence. ${ }^{21}$ Although Makurdi is an urban area, many parts of the town have concentration of low-income subjects who are farmers and fishermen. The people living in these areas have virtually the same risk factors as those in the rural areas.

Of the known risk factors, being older, having close contact with people known to be positive, and having multiple sexual partners were significantly associated with being infected. This is as expected.

For HCV, Buruku local government again had the highest prevalence of $3 \%$ and Ogbadibo the lowest prevalence of $0 \%$. Previous transfusion was a risk factor. This may be because many blood transfusion services in the rural areas screen only for HIV and HBV. Only well-established secondary and tertiary centers know the need and screen for HCV. Hepatitis $\mathrm{C}$ virus may continue to be transmitted through blood transfusion until the personnel at lower levels of health care are properly educated and enabled to screen for HCV before transfusion.

This study has demonstrated that HBV and HCV prevalence in Benue state general population is lower than previous studies suggested, probably because of the fact that this is a study based on the general population, whereas previous studies were based on selected adult populations. Immunization of children for hepatitis B, which, was started in 2004, might also have had impact on the prevalence. This needs to be determined by further studies. If a new nationwide population study confirms this lower prevalence, Nigeria may be moved from a high to a medium-endemicity country.

The limitation of this study is the use of rapid diagnostic tests instead of ELISA, which is the gold standard. Although all precautions were taken to make sure the findings of positive and negative tests were genuine by comparing them with positive and negative controls based on ELISA, this is still accepted as a limitation. Funding and logistics militated against the use of ELISA. 
The rest of the data are being analyzed to identify the impact of immunization, clear risk factors, and knowledge and practices of the populations that can be used in implementing preventive measures.

Received August 31, 2019. Accepted for publication January 13, 2020.

Published online February 10, 2020.

Acknowledgments: The American Society of Tropical Medicine and Hygiene (ASTMH) assisted with publication expenses.

Financial support: The study was partially funded by the Grant UAM/ AACPHCM/AB/NOL1 from the Ahmadu Alli Centre, University of Agriculture, Makurdi.

Disclosures: Phillips Pharmaceuticals Limited (Nigeria) provided some of the test kits used in the study. Hephzibah Obekpa of the University of Agriculture, Makurdi, worked on the initial statistics, which were then crosschecked by one of us.

Authors' addresses: Abraham O. Malu, Department of Medicine, Jos University Teaching Hospital, Jos, Nigeria, and Department of Medicine, Benue State University Teaching Hospital, Makurdi, Nigeria, E-mail: aomalu@gmail.com. Godwin I. Achinge and Solomon A. Obekpa, Department of Medicine, Benue State University, Makurdi, Nigeria, E-mails: godwinachinge@yahoo.com and obeksolomon@ gmail.com. Priscilla M. Utoo, Department of Epidemiology and Community Health, Benue State University, Makurdi, Nigeria, E-mail: priscautoo@gmail.com. Jonathan T. Kur, Public Health, Ministry of Health, Makurdi, Nigeria, E-mail: jonathanternakur@yahoo.com.

\section{REFERENCES}

1. WHO, 2017. Global hepatitis report. Available at: https://www.who.int/ hepatitis/publications/global-hepatitis-report2017/en/. Accessed March 17, 2019.

2. Kramvis A, Kew M, 2007. Epidemiology of hepatitis B virus in Africa, its genotypes and clinical associations of genotypes. Hepatol Res 37 (Suppl 1): 9-19.

3. Apurva AM, Jordan JF, 2007. Viral hepatitis and HIV in Africa. AIDS Rev 9: 25-39.

4. Olayinka AT et al., 2016. Seroprevalence of hepatitis B in Nigeria: a national survey. Am J Trop Med Hyg 95: 902-907.

5. Harry TO, Bajani MD, Moses AE, 1994. Hepatitis B virus infection among blood donors and pregnant women in Maiduguri, Nigeria. East Afr Med J 70: 596-597.

6. Akani $\mathrm{Cl}$, Ojule AC, Opurum HC, Ejilemele AA, 2005. Seroprevalence of HBsAg in pregnant women in Port Harcourt. Niger Postgrad Med J 12: 266-270.

7. Agbede OO, Iseniyi JO, Kolewale MO, Ojuawo A, 2007. Risk factors and seroprevalence of hepatitis $B$ antigenemia in mothers and their preschool children in llorin, Nigeria. Therapy 4: $67-72$.

8. Luka SA, Ibrahim MB, lliya SN, 2008. Seroprevalence of hepatitis $B$ surface antigen among pregnant women attending Ahmadu Bello University Teaching Hospital Zaria. Niger J Parasitol 29: 38-41.

9. Forbi JC, Onyemauwa N, Gyar SD, Oyeleye AO, Entonu P, Agwale $\mathrm{SM}, 2008$. High prevalence of hepatitis $\mathrm{B}$ virus among female sex workers in Nigeria. Rev Inst Med Trop Sao Paulo 50: 219-221.

10. Olokoba AB, Salawu FK, Danburam A, Desalu OO, Olokoba LB, Wahab KW, 2009. Viral hepatitis in voluntary blood donors in Yola, Nigeria. Euro J Sci Res 31: 329-334.

11. Achinge GI, Malu AO, Mbaave PT, Bitto TT, Shaahu VN, Mohammed H, 2013 Hepatitis B surface antigen seropositivity and knowledge of hepatitis transmission. High Med Res J 13: 36-40.

12. National Programme on Immunization and Partners, 2002. Five Years National Strategic Plan, 2003-2007. Abuja, Nigeria: National Programme on Immunization, 19-20.

13. Achinge GI, Malu AO, Mbaave PT, Bitto TT, Shaahu VN, Mohammed $\mathrm{H}$, Misauno MA, 2013. Prevalence of hepatitis $\mathrm{C}$ in Makurdi, north central Nigeria. IOSR J Dental Med Sci 7: 06-10.

14. Association of Public Health Physicians of Nigeria, (Lagos State Chapter), 2014. Hepatitis B \& C sero-prevalence survey among residents of Lagos State. Lagos State Ministry of Health Report.

15. Ikobah J, Okpara H, Elemi I, Ogarepe Y, Udoh E, Ekanem E, 2016. The prevalence of hepatitis $B$ virus infection in Nigerian children prior to vaccine introduction into the national programme on immunization schedule. Pan Afr Med J 23: 128.

16. World Health Organization, 2017. Prevalence of HBV infection (HBsAg) in the general population by WHO region, 2015. Global Hepatitis Report. Geneva, Switzerland: WHO, 11-12.

17. Heffernan A, Cooke GS, Nayagam S, Thursz M, Hallet TB, 2019. Scaling up prevention and treatment towards the elimination of hepatitis C: global mathematical model. Available at: https:// www.thelancet.com/action/showPdf?pii=S0140-6736\%2818\% 2932277-3. Accessed March 17, 2019.

18. Federal Ministry of Health, Federal Republic of Nigeria, 2015: National Policy on Control of Viral Hepatitis B \& C in Nigeria. Abuja, Nigeria: Federal Ministry of Health.

19. Nwogoh B, Ikpomwen OD, Isoa EM, 2011: Donor blood procurement and the risk of transfusion transmissible viral infections in a tertiary health facility in south-south Nigria. Niger Med J 52: 227-229.

20. Aneke JC, Okocha CE, 2017. Blood transfusion safety; current status and challenges in Nigeria. Asian J Transfus Sci 11: 1-5.

21. Qu JB, Zhang ZW, Shimbo S, Watanabe T, Nakatsuka H, Matsuda-Inoguchi N, Higashikawa K, Ikeda M, 2000. Urbanrural comparison of $\mathrm{HBV}$ and $\mathrm{HCV}$ infection prevalence in eastern China. Biomed Environ Sci 13: 243-253. 